\title{
Plasticity of cell migration: a multiscale tuning model
}

\author{
Peter Friedl ${ }^{1,2}$ and Katarina Wolf ${ }^{1}$ \\ 'Department of Cell Biology, Nijmegen Centre for Molecular Life Sciences, Radboud University Nijmegen, 6500 HB Nijmegen, Netherlands \\ ${ }^{2}$ Rudolf Virchow Center, Deutsche Forschungsgemeinschaft Research Center for Experimental Biomedicine and Department of Dermatology, University of Würzburg, \\ 97980 Würzburg, Germany
}

Cell migration underlies tissue formation, maintenance, and regeneration as well as pathological conditions such as cancer invasion. Structural and molecular determinants of both tissue environment and cell behavior define whether cells migrate individually (through amoeboid or mesenchymal modes) or collectively. Using a multiparameter tuning model, we describe how dimension, density, stiffness, and orientation of the extracellular matrix together with cell determinants-including cell-cell and cell-matrix adhesion, cytoskeletal polarity and stiffness, and pericellular proteolysis-interdependently control migration mode and efficiency. Motile cells integrate variable inputs to adjust interactions among themselves and with the matrix to dictate the migration mode. The tuning model provides a matrix of parameters that control cell movement as an adaptive and interconvertible process with relevance to different physiological and pathological contexts.

\section{Introduction}

Cell migration is a complex and heterogeneous process executed by all nucleated cell types at a given time window of their development. For most cells, including epithelial, stromal, and neuronal cells, migration phases are confined to morphogenesis and cease with terminal differentiation toward intact tissue to become reactivated only for tissue regeneration or neoplastic processes. For other cell types, such as leukocytes, migration is integral to their function and maintained throughout their life span. Some cell types migrate only in the context of a defined substrate, such as epithelial cells moving along a basement membrane but not through interstitial tissues, whereas other cell types, including leukocytes, are versatile, as they interact with and migrate within virtually any substrate present in the body. Thus, although the same basic process is executed (i.e., cell translocation along or through tissue structures), each cell type exerts migration in different contexts using distinct molecular repertoires and extracellular guidance cues. We here

Correspondence to Peter Friedl: P.Friedl@ncmls.ru.nl; or Katarina Wolf: K.Wolf@ ncmls.ru.nl summarize extra- and intracellular molecular parameters that regulate cell migration and integrate them into a parameter "matrix" to better classify how cell migration modes are being both achieved and modulated.

\section{The modes of cell migration}

The mode of cell migration was originally classified based on the morphology of migration patterns. This terminology was then extended to include molecular parameters, such as cytoskeletal organization, the type of cell-matrix interaction and force generation, and the modification of the tissue structure imposed by migrating cells (Friedl et al., 1998b; Thiery, 2002; Friedl, 2004; Lämmermann and Sixt, 2009; Sanz-Moreno and Marshall, 2009). As main categories, cell move either individually (amoeboid or mesenchymal) or collectively (the migration of cohesive multicellular units; Fig. 1 and Table I; Friedl, 2004). Although these terms are arguably arbitrary and the molecular discrimination between the certain modes is incomplete, they help to simplify and categorize an otherwise diffuse literature and allow dissection of the molecular machineries underlying each mode.

Amoeboid migration commonly refers to the movement of rounded or ellipsoid cells that lack mature focal adhesions and stress fibers (Friedl et al., 2001; Lämmermann and Sixt, 2009). There are two subtypes of amoeboid movement. The first is the rounded, blebby migration of cells that do not adhere or pull on substrate but rather use a propulsive, pushing migration mode (Fackler and Grosse, 2008; Sanz-Moreno and Marshall, 2009). The second occurs in slightly more elongated amoeboid cells that generate actin-rich filopodia at the leading edge that engage in poorly defined, weak adhesive interaction with the substrate (Fig. 1; Yoshida and Soldati, 2006; Smith et al., 2007). In a special case of amoeboid movement, terminally matured nonadhesive dendritic cells produce dynamic actin-rich dendrites, instead of blebs, at their leading edge that cause these cell to become entangled with the ECM substrate during migration (Gunzer et al., 1997; Lämmermann et al., 2008). Individual cells with high levels of attachment and cytoskeletal contractility develop mesenchymal migration, which involves focalized cell-matrix interactions and movement in a fibroblast-like

(C) 2009 Friedl and Wolf This article is distributed under the terms of an AttributionNoncommercial-Share Alike-No Mirror Sites license for the first six months after the publication date (see http://www.jcb.org/misc/terms.shtml). After six months it is available under a Creative Commons License (Attribution-Noncommercial-Share Alike 3.0 Unported license, as described at http://creativecommons.org/licenses/by-nc-sa/3.0/). 
Morphology
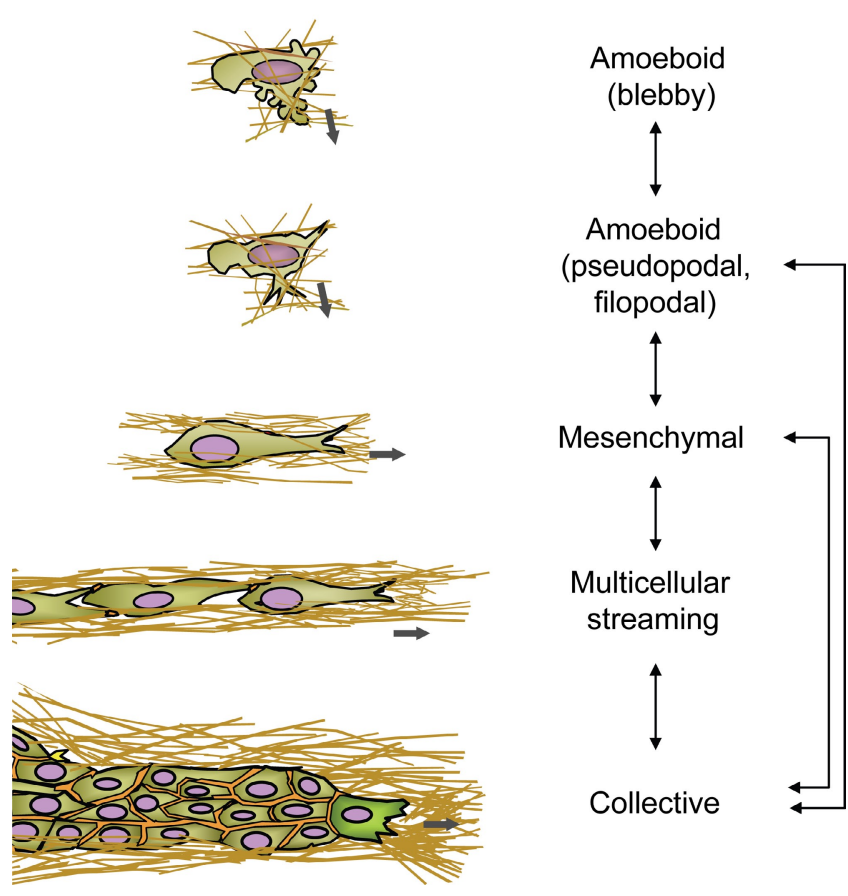

Figure 1. Cell morphologies, migration modes, and transitions. The nomenclature of interstitial migration modes is based on typical cell morphology (rounded or spindle-shaped) and pattern (individual, loosely connected, or collective). Each migration mode is governed by a set of molecular mechanisms (see details in Table I and Fig. 2), the regulation of which can change the style of migration. Most widely studied examples for alterations of migration mode are the mesenchymal-to-amoeboid transition or the collective-to-individual transition. The thick gray arrows indicate the direction of migration.

manner (Kaye et al., 1971; Maaser et al., 1999; Grinnell, 2008). The migration of individual cells that transiently form and resolve cell-cell contacts while moving along a common track is termed chain migration or cell streaming (Davis and Trinkaus, 1981; Teddy and Kulesa, 2004). Finally, the maintenance of stringent cell-cell adhesions can lead to partial or complete silencing of migration activity in cells inside a group yet supports cytoskeletal activity at outward edges or at basal cell-substrate contacts. The resulting collective migration occurs in the form of multicellular tubes, strands, irregularly shaped masses, or sheets (Vaughan and Trinkaus, 1966; Friedl et al., 1995; Farooqui and Fenteany, 2005).

Most migration modes, although they can be observed in (mostly experimental) 2D environments, occur in vivo in the context of 3D tissue environments (Even-Ram and Yamada, 2005). Conversely, in vivo, some migration modes are dedicated exclusively to 2D environments. Epithelial keratocytes and keratinocytes migrate across flat 2D substrate using rapid spread-out cell gliding (Keren et al., 2008) that, if cell-cell junctions between the cells remain intact, form a collectively migrating 2D cell sheet (Vaughan and Trinkaus, 1966; Farooqui and Fenteany, 2005). In different cell types, these modes of migration are associated with different efficiencies yielding varying migration speeds, such as the fast migratory scanning of single leukocytes, the relatively slow invasive migration of fibroblasts into provisorial wound matrix, or, at the slowest end, the collective migration during organ formation (Table I; Friedl et al., 1998b).

Single-cell and collective migration modes serve mutually exclusive purposes during morphogenesis, tissue regeneration, and in pathological conditions. Collective cell migration is essential in building, shaping, and remodeling complex tissues and tissue compartments, such as epithelia, ducts, glands, and vessels, but also contributes to cancer progression by local invasion (Alexander et al., 2008; Friedl and Gilmour, 2009). In contrast, single-cell migration allows cells either to cover local distances and integrate into tissues, such as neural crest cell migration, or to move from one location in the body to another and fulfill effector functions, such as immune cell trafficking (Friedl, 2004; Teddy and Kulesa, 2004; Lämmermann and Sixt, 2009). The latter process is recapitulated during cancer metastasis to distant sites (Thiery, 2002). Although not all molecular determinants of each migration mode are fully understood, some key parameters have been identified as "checkpoints" to either maintain a given migration type, or, by an increase or decrease of activity, initiate transitions.

\section{Determinants of cell migration}

The common process underlying all migration modes of nucleated mammalian cells is polarized actomyosin-driven shape change of the cell body (Lauffenburger and Horwitz, 1996; Ridley et al., 2003; Keren et al., 2008). This basic program is regulated and "shaped" by several distinct yet interdependent physical and molecular parameters of the tissue and the cell itself that together determine how a cell migrates (Fig. 2). The extracellular environment strongly impacts migration type and efficiency by providing ECM ligands of different macromolecular and structural organization, which includes dimension, density, stiffness, and orientation. In response to environmental determinants, the actomyosin cytoskeleton adapts in a dynamic manner and generates different geometries in space and time, ranging from flat and spread out to roundish, elongated, or multipolar shapes (Grinnell, 2008; Keren et al., 2008). To transmit actomyosin-driven forces to surrounding tissue structures, the cell either develops actin-polymerization-driven protrusions that bind to adhesion sites of the tissue through adhesion receptors (Yamada et al., 2003), or it utilizes poorly adhesive intercalation and propulsion (Paluch et al., 2006a). In both cases, subsequent to leading edge protrusion, actomyosin contraction leads to retraction of the cell rear and translocation of the cell body (Paluch et al., 2006a; Lämmermann and Sixt, 2009). The cyclic repetition of protrusion, interaction with the extracellular environment, and retraction of the cell rear result in cell movement that, depending on the molecular repertoire of the cell, yields distinct migratory modes (Lauffenburger and Horwitz, 1996; Friedl and Wolf, 2009). Additional parameters impacting the type and efficiency of cell migration are the availability of surface proteases that remodel the surrounding tissue (Wolf and Friedl, 2009), and whether the cells retain stringent, loose, or no cell-cell junctions (Friedl and Gilmour, 2009). 
Table I. Different migration modes and selected determinants

\begin{tabular}{|c|c|c|c|c|c|}
\hline Migration mode & Cell types & ECM determinants & Cell determinants & Related transitions & References \\
\hline \multicolumn{6}{|l|}{ Single } \\
\hline $\begin{array}{l}\text { Amoeboid, } \\
\text { blebby }\end{array}$ & $\begin{array}{l}\text { Zebrafish macrophage, } \\
\text { some stem cells }\end{array}$ & $\begin{array}{l}\text { Poorly adhesive; soft } \\
\text { embryonic connective } \\
\text { tissue; obligate 3D }\end{array}$ & $\begin{array}{c}\text { Asymmetric bleb-rich cortical } \\
\text { actomyosin cytoskeleton, low } \\
\text { polarity; low migration speed } \\
\text { (below } 1 \mathrm{\mu m} / \mathrm{min} \text { ) }\end{array}$ & $\begin{array}{l}\text { Blebby-to-pseudopodal } \\
\text { transitions }\end{array}$ & $\begin{array}{l}\text { Blaser et al., 2006; } \\
\text { Yoshida and Soldati, } \\
2006\end{array}$ \\
\hline $\begin{array}{l}\text { Amoeboid, } \\
\text { pseudopodal }\end{array}$ & $\begin{array}{l}\text { Leukocytes, including } \\
\text { dendritic cells; } \\
\text { Dictyostelium } \\
\text { discoideum }\end{array}$ & $\begin{array}{l}\text { Loose primordial or } \\
\text { mature connective tissue; } \\
2 D \text { or } 3 D\end{array}$ & $\begin{array}{l}\text { Poorly adhesive, no formation } \\
\text { of focal adhesions; Rac-driven } \\
\text { anterior protrusion with counter- } \\
\text { balance by Rho/ROCK in other } \\
\text { cell parts; relatively rapid } \\
\text { migration (10 } \mathrm{m} / \mathrm{min})\end{array}$ & $\begin{array}{l}\text { Amoeboid-to- } \\
\text { mesenchymal } \\
\text { transition }\end{array}$ & $\begin{array}{l}\text { Yoshida and Soldati, } \\
\text { 2006; Lämmermann } \\
\text { et al., } 2008\end{array}$ \\
\hline Mesenchymal & $\begin{array}{l}\text { Fibroblasts, neural crest } \\
\text { cells, sarcoma cells, } \\
\text { dedifferentiated cancer } \\
\text { cells of different origin }\end{array}$ & $\begin{array}{l}\text { Loose or dense primor- } \\
\text { dial or mature } \\
\text { connective tissue; } \\
\text { usually associated with } \\
\text { fibrin or collagen } \\
\text { remodeling }\end{array}$ & $\begin{array}{l}\text { Moderately to highly adhesive; } \\
\text { focal interactions with ECM; } \\
\text { high contractility; high anterior } \\
\text { Rac activity counterbalanced } \\
\text { by Rho in other cell parts; slow } \\
\text { migration }(0.1-1 \mu \mathrm{m} / \mathrm{min})\end{array}$ & $\begin{array}{l}\text { Mesenchymal-to- } \\
\text { amoeboid transition; } \\
\text { mesenchymal-to- } \\
\text { epithelial/collective } \\
\text { transition }\end{array}$ & $\begin{array}{l}\text { Wolf et al., 2003a, } \\
\text { 2007; Grinnell, 2008; } \\
\text { Paňková et al., 2009; } \\
\text { Thiery, } 2002\end{array}$ \\
\hline \multicolumn{6}{|l|}{ Multicellular } \\
\hline $\begin{array}{l}\text { Chain migration, } \\
\text { cell streaming }\end{array}$ & $\begin{array}{l}\text { Neural crest cells, } \\
\text { fibroblasts }\end{array}$ & Joint ECM tracks? & $\begin{array}{l}\text { Individual cells with temporary } \\
\text { tiplike cell-cell contacts }\end{array}$ & $\begin{array}{l}\text { Migration arrest and } \\
\text { integration into } \\
\text { terminal tissue }\end{array}$ & $\begin{array}{c}\text { Davis and Trinkaus, } \\
1981 \text {; Kulesa and } \\
\text { Fraser, } 2000\end{array}$ \\
\hline Collective & $\begin{array}{l}\text { Dictyostelium at slug } \\
\text { stage, lateral line } \\
\text { (zebrafish), border cells } \\
\text { (Drosophila egg cham- } \\
\text { ber), sprouting vessels, } \\
\text { many epithelial and } \\
\text { other cancer types }\end{array}$ & $\begin{array}{l}\text { Any } 2 D \text { and } 3 D \text { ECM } \\
\text { environment, resulting } \\
\text { in cohesive sheets or } \\
3 D \text { strands, tubes, } \\
\text { clusters or amorphous } \\
\text { masses }\end{array}$ & $\begin{array}{l}\text { Intact and stable cell-cell } \\
\text { adhesions; coordination of } \\
\text { multicellular leading edge } \\
\text { protrusion and rear retraction; } \\
\text { cell-cell communication } \\
\text { during migration }\end{array}$ & $\begin{array}{l}\text { Collective-to-single cell } \\
\text { transitions (epithelial/ } \\
\text { collective-to-mesen- } \\
\text { chymal; collective-to- } \\
\text { amoeboid) }\end{array}$ & $\begin{array}{l}\text { Hegerfeldt et al., } \\
\text { 2002; Thiery, 2002; } \\
\text { Alexander et al., 2008; } \\
\text { Friedl and Gilmour, } \\
2009\end{array}$ \\
\hline Keratocyte-like & Keratinocytes & $\begin{array}{l}\text { Obligate 2D surface } \\
\text { or tissue }\end{array}$ & $\begin{array}{c}\text { Persistent gliding-type } \\
\text { migration of spread-out cells } \\
\text { with broad continuous } \\
\text { leading lamella cadherin-based } \\
\text { cell-cell junctions }\end{array}$ & Not known & Keren et al., 2008 \\
\hline
\end{tabular}

\section{ECM determinants}

The ECM provides a structural and molecular frame for the moving cell body and thereby impacts the mode and efficiency of cell migration.

ECM dimension. Extracellular tissue structures encountered by migrating cells are either flat $2 \mathrm{D}$ sheets or $3 \mathrm{D}$ tissue networks. Cell migration across 2D surfaces occurs during reepithelialization of wounds or the scanning of leukocytes along the inner blood vessel wall or inner epithelial surfaces (Farooqui and Fenteany, 2005). Hallmarks of 2D migration are the requirement of unilateral adhesion to the substrate, which provides stable-enough but transient attachment; a flattened, spread-out cell morphology guided by a leading lamellipod; and, due to the flat geometry of the substrate, a largely barrierfree migration (Ridley et al., 2003; Farooqui and Fenteany, 2005; Keren et al., 2008; Vitorino and Meyer, 2008). In contrast, when cells move through 3D interstitial tissue consisting of a network of interwoven collagen fibers, which impose space limitations against the moving cell body, their morphology undergoes characteristic changes. First, spread-out morphology is abandoned in favor of a spindle-like shape; second, instead of lamellipodia formation, with its unilateral polarization to the underlying substrate, leading edge protrusion occurs by formation of thin tiplike cylindrical pseudopodia that orient in three dimensions; and third, the cell either deforms its shape to accommodate small tissue gaps or executes remodeling of the ECM structure by pericellular proteolysis (Maaser et al., 1999; Wolf et al., 2003a; Jiang and Grinnell, 2005).

ECM density and gap size. In vivo, interstitial tissues greatly vary in structural organization, such as collagen content, fibrillar texture, fiber bundle thickness, and interfiber porosity. In vivo, migration efficiency is optimal at pore diameters that match or range slightly below the diameter of polarized cells. If the tissue gaps exceed the cell size, migration rates decrease (Haston et al., 1982; Harley et al., 2008) because of a loss of most cell-fiber interactions until only very few or even a single fiber remain engaged with the cell body; the latter is termed "1D" migration (Doyle et al., 2009). Conversely, if pores range below the cell diameter, cells slow down and eventually may become trapped due to the physical hindrance (unpublished data; Haston et al., 1982; Harley et al., 2008). In response to extracellular confinement, migrating cells elongate to a spindlelike shape and thereby stretch and reduce their cell diameter, whereas large pore sizes favor cell rounding, a hallmark of amoeboid migration (unpublished data; Fig. 2).

The deformability of the cell and its most rigid compartment, the nucleus, is controlled by nuclear lamins A/C, which mechanically stabilize the nuclear membrane and potentially impact the minimum tissue gaps that can be transmigrated (Lammerding et al., 2006; Dahl et al., 2008). Besides shape 


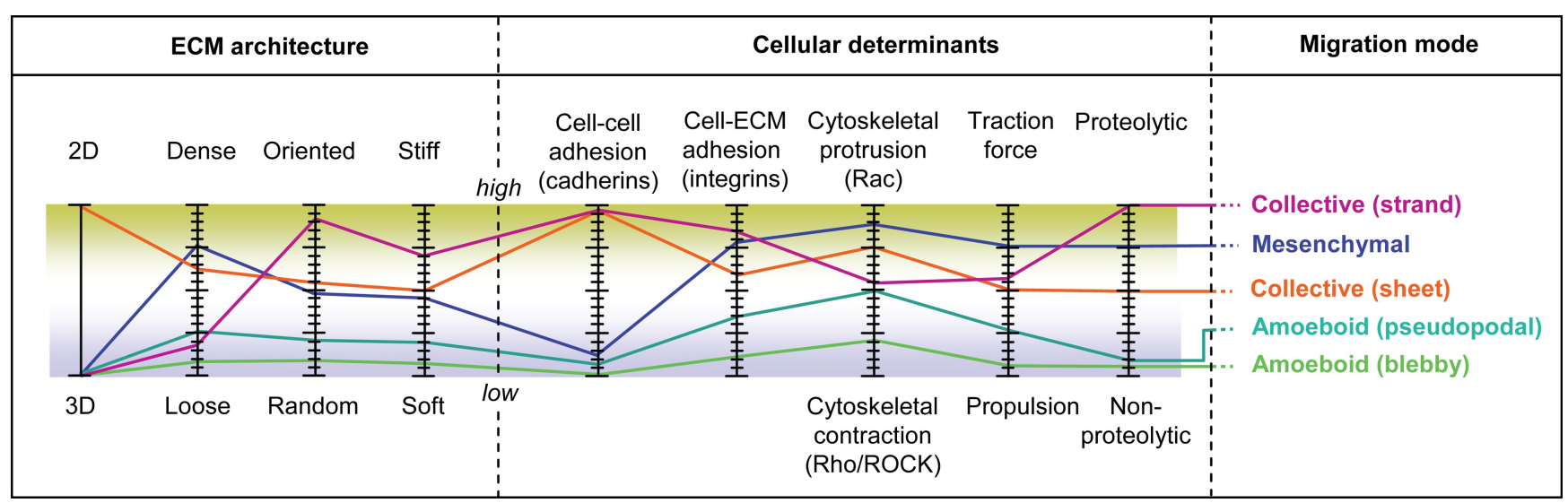

Figure 2. The tuning model of cell migration. An integrated multiscale model to combine multiple interdependent parameters that impact migration mode. Each parameter is experimentally testable individually; however, in most cases they are interconnected with others (see text for details). Approximated parameter profiles of selected migration modes are indicated (colored lines). Modulation by increasing or decreasing the magnitude of any parameter may impact the resulting migration mode as well as the input strength of coregulated parameters. The format of the tuning model mimics the popular display of a graphic equalizer, which is integral to modern media display programs (e.g., Windows Media Player or QuickTime); the graphic interface serves to adjust the intensity of different wavelengths of the phono output independently to modify the sound profile.

adaptation, cells that can proteolytically cleave ECM structures counteract physical hindrance by enlarging pores and forming trails of variable caliber so they match their own diameters (Wolf et al., 2007). Thus, the ability of the cell to deform relative to the available space and to remodel tissues through proteolysis determines both the mode and efficiency of migration in 3D ECM.

Stiffness. ECM stiffness (synonymous with rigidity) or elasticity (synonymous with pliability), which can be measured as elastic modulus, depends on molecular properties of the tissue, including collagen content, fiber thickness, and the extent of intrafibrillar cross-links, which define the stability and deformability of the tissue scaffold (Shoulders and Raines, 2009). Cells detect matrix rigidity via integrin-mediated adhesions and downstream mechanosensor protein signaling (i.e., via talin and p130CAS; Giannone and Sheetz, 2006). Increased substrate stiffness reinforces cell protrusions at outward edges so that focal adhesions form and become reinforced by RhoA-mediated actomyosin contraction, ultimately leading to cell spreading, the generation of high-traction force, and elongated cell movement (Peyton et al., 2008; Ulrich et al., 2009). Conversely, soft matrix does not reinforce focal adhesion formation and cytoskeletal contractility; rather, it supports cell rounding (Ulrich et al., 2009). Consequently, matrix rigidity stimulates directed cell migration, similar to chemotaxis, so that cells tend to migrate toward substrate of greater stiffness, a process termed durotaxis (Lo et al., 2000; Li et al., 2005; Isenberg et al., 2009).

Orientation. Connective tissue comprises a range of physical textures, ranging from loose and random to highly aligned structures (Petrie et al., 2009; Wolf et al., 2009). All mobile cells show a tendency to align in parallel along oriented structural discontinuities, such as at interfaces of muscle fibers, blood vessels, or ECM fiber strands and patterns created by the cells themselves (Provenzano et al., 2008; Petrie et al., 2009). Contact guidance along such structures is mediated by mechanosensory integrins that, together with Rho/ROCK-mediated cytoskeletal stiffening, provide directional persistence (Dickinson et al., 1994; Provenzano et al., 2008; Petrie et al., 2009). Although aligned fiber orientation in collagen-rich ECM does not seemingly impact cell shape (Provenzano et al., 2008), it favors multicellular streaming in chainlike patterns in 3D tissue (Friedl and Wolf, 2009) and migration of 2D cell sheets along tissue clefts (unpublished data).

In summary, different ECM environments provide an array of interconnected input parameters that modulate cell adhesion and cytoskeletal organization, and directly impact cell shape, guidance, and mode of migration.

\section{Cell determinants}

Cell-cell adhesion. A key determinant of how cells move is whether cell-cell junctions are retained or not, resulting in either collective or single-cell migration, respectively (Vitorino and Meyer, 2008; Friedl and Gilmour, 2009). Cell-cell adhesion is mainly mediated by cadherins, including E-cadherin in epithelial cells, VE-cadherin in endothelial cells, and N-cadherin in stromal cells (Ewald et al., 2008; Vitorino and Meyer, 2008; Friedl and Gilmour, 2009). As opposed to individually migrating cells, during collective migration, the rear of the front cell retains intact cell-cell junctions to the successor cell, thereby mechanically holding the cells together and augmenting the efficiency of paracrine cell-cell signaling and multicellular coordination (Fig. 1). Coordinated cycles of protrusion and rear retraction of the front cells as well as of cells inside the group that engage with underlying substrate lead to movement as a multicellular unit (Farooqui and Fenteany, 2005; Blanchard et al., 2009). If cell-cell junctions are intermittent or less stable, multicellular streaming in a loose tail-to-head fashion results in the coordinated but individual migration of many cells through the tissue, with repetitive short-lived contacts between cells that are resolved and reestablished upon further migration (Fig. 1; Teddy and Kulesa, 2004). Lastly, if cell-cell contacts are absent, cells move independently in both speed and direction (Hegerfeldt et al., 2002). Thus, the presence of stable or transient cell-cell junctions, or their absence, determines 
whether collective translocation, cell streaming, or single-cell migration, respectively, is being generated.

Cell-matrix adlhesion. Cell adhesions to ECM ligands are predominantly generated by integrins via coupling to cytoskeletal and signaling proteins. The strength and turnover rates of cell attachments to the extracellular environment determine which cell shapes and forces are being generated during migration (Ridley et al., 2003). Distinct cell types use adhesive strength over different magnitudes, ranging from strong adhesion by stromal fibroblasts or myoblasts (Huttenlocher et al., 1996), to moderate adhesion of epithelial and endothelial cells (Zhang et al., 2006; Schober et al., 2007), to weak adhesion forces of rapidly gliding fish keratocytes and crawling leukocytes (Friedl et al., 1998b; Keren et al., 2008; Lämmermann et al., 2008). High integrin expression levels are mandatory for high-attachment forces, but are also associated with relatively slow turnover of adhesion sites (Friedl et al., 1998b; Mc Henry et al., 2008) and, consequently, associated with slow migration (Palecek et al., 1997). As an underlying mechanism, integrins and downstream mechanotransducing adaptors, such as p130CAS, become activated with increased mechanical tension and, in turn, further strengthen focal adhesions and actin stress fiber formation (Tamada et al., 2004; Sawada et al., 2006). Strong cell-substrate adhesions thus promote cell contractility and the formation of elongated spread-out (2D) or spindleshaped (3D) morphologies in many cell types, including fibroblasts, smooth muscle cells, and neoplastic cells (Lauffenburger and Horwitz, 1996; Friedl et al., 1998b; Maaser et al., 1999; Jiang and Grinnell, 2005).

If cell adhesion is reduced to a moderate or low level, such as by interfering with the integrin-talin axis, focal adhesions and stress fibers do not form or do not reach full maturation (Zhang et al., 2008). As a consequence, the cells convert to a less elongated or spread-out morphology, generate smaller lamellipodia and pseudopodia, and transmit limited adhesion strength toward the substrate (Zhang et al., 2008). Rapidly moving lymphocytes and neutrophils that still adhere to ECM and other ligands but do not form focal adhesions or stress fibers constitutively use the pseudopodal amoeboid type of movement (Friedl et al., 1998a; Smith et al., 2007).

At the very low end of cell adhesion strength, cells are unable to form unilateral attachments to 2D ECM substrate and thus fail to spread out, form lamellipodia, and move, whereas in a 3D environment, they move by amoeboid blebbing or dendritic intercalation (Haston et al., 1982; Fackler and Grosse, 2008; Lämmermann and Sixt, 2009). Given such low adhesion capability, the mechanisms that generate force in this blebby (or dendritic) amoeboid translocation remain to be shown. Likely, the irregular cell shape maintained by cortical actin provides high cytoskeletal rigidity locally, which allows mechanical intercalation between anterior parts of the cell with the surrounding tissue while the rear part of the cell retracts (Blaser et al., 2006; Paluch et al., 2006a; Lämmermann and Sixt, 2009).

Cell protrusion and rounding. Cell protrusions control leading edge dynamics and the migration mode in at least two distinct ways. First, the protrusion of pseudopodia, filopodia, and lamellipodia that adhere to cell and ECM substrates is directed by the small GTPases Rac and Cdc42 (Nobes and Hall, 1999; Sanz-Moreno and Marshall, 2009). Consequently, high Rac activity conveys leading edge extension, elongated morphology, focal integrin engagement, and mesenchymal migration (Nobes and Hall, 1999; Sahai and Marshall, 2003; Sanz-Moreno et al., 2008). Second, bleb-like protrusions that contain cortical actin filaments are nonadhesive or poorly adhesive but contribute to lateral anchoring ("elbowing") of the cell to tissue structures during actomyosin-mediated rear retraction (Paluch et al., 2006a,b; Fackler and Grosse, 2008). In most cells, Rac-mediated protrusion of the leading edge is counterbalanced by Rho/ROCK signaling, which controls actomyosinmediated retraction of the trailing edge. Together, they form a cyclic balance in distinct regions of the cell and contribute, concurrently, to the migration cycle (Ridley et al., 2003; SanzMoreno and Marshall, 2009). High Rac activity generates cell elongation and mesenchymal migration, whereas active Rho in the presence of little or no Rac activity supports rounded cell shapes associated with amoeboid pseudopodal or blebbing migration, respectively (Sahai and Marshall, 2003; SanzMoreno et al., 2008). Besides inducing cell protrusions, active Rac negatively regulates Rho/ROCK signaling and inhibits cell rounding, whereas active Rho/ROCK limits Rac, which inhibits cell extension and elongation (Sanz-Moreno et al., 2008).

The formation and elongation of cell protrusions during migration are further controlled by tubulins. Posttranslational tubulin acetylation supports high microtubule stability and is associated with mesenchymal movement, whereas microtubules composed of deacetylated tubulin are subject to enhanced depolymerization by the microtubule-destabilizing factor stathmin and therefore support a rounded, amoeboid migration mode (Piperno et al., 1987; Belletti et al., 2008; Berton et al., 2009). Whether tubulin stability dictates cell shape by modulating to the balance between Rac and Rho activity or by other mechanisms, such as delivery of cargo or a direct mechanical function, is unknown.

Mode of force generation. The force required to move a cell body forward is generated by two principal and often interdependent physical mechanisms: cell propulsion, which leads to forward pushing of the cell body; or traction force generated by pulling of an ECM substrate. A phase of actin polymerization-driven forward pushing of the plasma membrane is indispensible for leading edge protrusion, so it is included in most migration types (Lauffenburger and Horwitz, 1996). In adhesive cells, pushing then leads to local adhesion, cytoskeletal anchorage, and, in a second phase, focal adhesion maturation and pulling on ECM substrate by actomyosin contraction (Ridley et al., 2003; Zhang et al., 2008). Pulling is proportional to adhesion strength and cytoskeletal contractility, such as in fibroblasts and myoblasts, to generate forces sufficient for substrate contraction (Beningo et al., 2001; Miron-Mendoza et al., 2008). In contrast, if leading edge protrusion is coupled to low adhesion force, amoeboid pseudopodal migration occurs at very low traction force, as in moving neutrophils (Smith et al., 2007; Wang, Y.-L., personal communication). On the very low end of adhesion and force generation, amoeboid blebbing cells tend to 
lack any attachment to 2D surfaces but rather float and oscillate on the spot (unpublished data; Paluch et al., 2006a). However, if included in a loose 3D ECM, such as a collagen matrix or matrigel, blebby cells that are deficient in pseudopodia or filopodia are still able to connect to the $3 \mathrm{D}$ substrate and generate movement, despite negligible attachment forces (Blaser et al., 2006; Sanz-Moreno et al., 2008). Thus, whereas mesenchymal migration depends on alternating pushing/pulling cycles, amoeboid migration is mechanically equally complex and comprises stronger pushing combined with a small or completely absent phase of adhesive pulling of the substrate.

Protease functions. Depending on the deformability of the migrating cell and the size of gaps and trails available in the 3D tissue, cells proteolytically remodel surrounding ECM and generate gaps, a hallmark of mesenchymal migration; otherwise, they move without engaging proteases by filling available spaces with their cell body (Friedl and Wolf, 2003a, 2009). In interstitial tissues, MT1-MMP is rate-limiting for collagen degradation, as it executes pericellular proteolysis of collagen fibers that physically impede the moving cell (Wolf et al., 2007; Sabeh et al., 2009). After cleavage, collagen fibers become displaced and realigned, which generates tubelike matrix gaps and trails of least resistance (Friedl and Wolf, 2008). In collagen-rich interstitial tissue, MT1-MMP is further involved in the remodeling of already existing trails to even larger macrotracks, which then accommodate the collective invasion of multicellular strands (Wolf et al., 2007).

In contrast to mesenchymal cells that are usually large, smaller amoeboid leukocytes employ much faster movement that lacks signs of pericellular proteolysis of the 3D interstitial substrate (Friedl and Wolf, 2003a). A mechanism of coping with narrow trails is cell deformation and squeezing through the pores so that extracellular structures imprint into the cell body and form local zones of cell compression (Wolf et al., 2003b). If tissue densities are high, such as in basement membranes or dense connective tissue, inhibition of pericellular proteolysis cannot be compensated by shape change; instead, cell bodies get stuck in narrow pores (Sabeh et al., 2004, 2009). Likewise, if proteolytic macropatterning is prevented by protease inhibition, collective cell invasion is ablated and only individual amoeboid dissemination persists (Wolf et al., 2007). Thus, proteolytic ECM remodeling is obligatory in tissues in which cell caliber and deformability fail to match available gaps and trails.

\section{The tuning model}

Because of its physical and molecular modularity, cell migration must be viewed as a consequence of a continuum of states that are determined by cell mechanics and signaling events. These cellular properties are integrated by the cell or cell groups in a given tissue environment. The tuning model predicts that several parameters simultaneously control how a cell migrates and that their combined magnitudes impact which migration type a cell adopts (Fig. 2). With the exception of ECM dimension, which is either $2 \mathrm{D}$ or $3 \mathrm{D}$, all other parameters are scalar; i.e., they can be absent or at low, intermediate, or high levels. Therefore, these parameters are assumed to be tunable and thereby control the migration mode and efficiency in a continuous rather than a discrete "on" or "off" manner. By increasing or decreasing their input, they "tune" how moving cells polarize and engage with encountered tissue substrate. Because all parameters act concurrently but at a different strength, each parameter profile (Fig. 2, colored lines) then generates a different type of migration. Whereas most molecular studies tend to address isolated parameters, the tuning model integrates several denominators in context and may help to understand cell migration as a multimodal cell function.

Each component, although experimentally amenable as an individual parameter, is interdependent and positively or negatively coregulated with other determinants. The density of fibrillar ECM is positively interconnected with stiffness and inversely proportional to pore size, so alterations of either parameter impacts the overall tissue geometry (unpublished data). Accordingly, integrin-mediated cell attachment to a deformable yet rigid substrate, but not to a soft substrate, enhances substrate tension and stiffness, which reinforces Rho-mediated traction force generation (Paszek et al., 2005; Peyton et al., 2008; Ulrich et al., 2009). Likewise, traction force generation requires sufficient adhesion mediated by integrins, some Rac-mediated protrusion, and Rho-mediated cytoskeletal contraction (Rhee and Grinnell, 2006). The physical tissue geometry is interdependent with protease acitivity of the cells; consequently, collective migration in 3D tissue depends on sufficiently high a priori porosity or the cell-mediated proteolytic generation of macrotracks (Wolf et al., 2007). Therefore, alteration of a given parameter has likely consequences for other interconnected determinants.

Plasticity: tuning the mode of migration At a given differentiation state, each cell type preferentially employs a particular "default" migration type, such as leukocytes using amoeboid migration, stromal cells moving by a mesenchymal mode, or epithelial cell sheets moving collectively (Friedl, 2004). However, in recent years, it has become clear that naturally occurring or experimentally induced modifications of either the environment or cell properties may result in striking adaptation reactions that alter the migration mode rather than abrogating migration per se. Because any parameter may become altered in the course of migration-such as the transition from dense to loose connective tissue, modulation of adhesion receptor expression, or the availability of cytoskeletal adaptor proteins due to altered gene expression-each alteration of parameter may prompt such secondary alteration of migration mode.

Because cell-cell junctions can form de novo and resolve again, individual and collective migration modes are interconvertible (Friedl and Gilmour, 2009). If multicellular cohesion is weakened by the down-modulation of cell-cell junctions, individual cells detach from the multicellular unit which, dependent on the molecular repertoire and environment encountered, disseminate individually. Epithelial-to-mesenchymal transition is involved in many developmental processes and in invasive cancers, and leads to the delamination of spindle-shaped cells that use integrin-mediated force generation for tissue invasion either as single cells or by multicellular streaming (Thiery, 2002; Carmona-Fontaine et al., 2008). Collective-to-amoeboid 
transition occurs when the detached individual cells disseminate using amoeboid migration (Hegerfeldt et al., 2002; Wolf et al., 2007). Conversely, if individually moving cells up-regulate cell-cell adhesion molecules, then cell aggregation leads to individual-to-collective transition (Thiery, 2002).

A central pathway controlling the interconversion between mesenchymal and rounded, amoeboid migration is the balance between Rac and Rho signaling (Sahai and Marshall, 2003). In many experimental examples, mesenchymal-toamoeboid transitions depend, directly or indirectly, on pathways that weaken Rac and/or strengthen Rho/ROCK signaling (SanzMoreno et al., 2008; Paňková et al., 2009; Sanz-Moreno and Marshall, 2009). Thus, upstream pathways that suppress Rac activity induce this conversion, including the activation of the GTPase-activating protein (GAP) ARHGAP22, which directly inhibits Rac (Sanz-Moreno et al., 2008); inhibition of the Racactivating guanine nucleotide exchange factor DOCK3/NEDD9 or of the down-stream Rac effector and Rho inhibitor WAVE-II (Sanz-Moreno et al., 2008); interference with Rab5-mediated endocytosis and recycling of Rac to cell protrusions (Palamidessi et al., 2008); and the inhibition of E3 ubiquitin ligase Smurf1, which enzymatically degrades Rho near the leading edge and thereby secures the dominance of Rac in cell protrusions (Sahai et al., 2007). Likewise, inhibition of chemokine-meditated Rac activation favors amoeboid movement in otherwise mesenchymal cells (Gérard et al., 2007). Pathways that activate Rho lead to mesenchymal-to-amoeboid transition, including inhibition of negative Rho regulators (e.g., p90RhoGAP) through an indirect, reactive oxygen species-dependent mechanism (Nimnual et al., 2003) or the activation of Ephrin2A receptor tyrosine kinase signaling, which indirectly activates Rho (Parri et al., 2009).

Alteration of adhesion force by modulating integrin function leads to similar plasticity. The transition from amoeboid myeloid precursor cells to adhesive elongated and contractile macrophages is initiated by the up-regulation and activation of $\beta 1, \beta 2$, and $\beta 3$ integrins (McNally and Anderson, 2002). Conversely, mesenchymal cells convert to amoeboid movement in experimental 3D matrices after limiting pathways that control focal adhesion formation, including inhibition of $\beta 1$ integrinmediated adhesion or of the tyrosine kinase cSrc (Carragher et al., 2006; Zaman et al., 2006). Plasticity imposed by altered tissue architecture occurs when cells transit from a 2D interface into 3D tissue. The initial spread-out or cuboidal 2D phenotype then converts toward a spindle-shaped mesenchymal phenotype with vertical penetration and migration into the 3D matrix (Alt-Holland et al., 2008). Lastly, in loose interstitial tissues with gaps that accommodate the cell body, the inhibition of surface protease activity causes a transition from proteasedependent mesenchymal migration to amoeboid migration involving shape change and squeezing without tissue remodeling (Wolf et al., 2003a, 2007).

Thus, alterations of cell-cell and cell-matrix adhesion, cytoskeletal signaling and mechanics, and protease function determine whether and how cells switch between distinct migration modes. These transitions of migration mode are best studied for cancer cells and likely contribute to the metastatic cascade (Friedl and Wolf, 2003b; Sanz-Moreno and Marshall, 2009), yet they are also relevant to cell migration and function in physiological contexts, such as the delamination of cells during morphogenesis and the distribution of stem cells or leukocytes in tissues and organs (Blaser et al., 2006; Lämmermann and Sixt, 2009).

\section{Outlook}

The multiparameter tuning model integrates observations from many different cell types and experimental models. The model thus may be helpful to understand and experimentally test the adaptability of cell movement and its consequence for tissue formation and remodeling, particularly in morphogenesis and cancer metastasis. The model may further be a useful starting point for computational modeling of cell migration in different contexts. Although the parameters and migration modes discussed here are best established for interstitial migration of cells in fibrillar collagen-rich tissues, they likely fail to sufficiently represent the movement of other cell types and tissue contexts. This may be the case particularly for cells of neural origin that predominantly move along scaffold tracks formed by other cells, rather than ECM, or cell trafficking across basement membrane during transendothelial migration or the early invasion of epithelial cancer. Likewise, complex movements in ductal gland or vessel formation represent special cases with complex topography, such as lumen formation and deposition of a basement membrane, which may require the inclusion of additional modules. Besides integrinmediated adhesion structures, special cases of cell-substrate interaction include cadherin- or ephrin-based cell-cell junctions that guide cell migration along cell scaffolds, and podosomes and invadopodia that degrade ECM underneath the cell body but not at leading edges. The contribution of these structures to force generation and the mode of migration remain to be established and, potentially, included in the model. Ultimately, although each parameter has its own contribution to how efficiently cells migrate, the model still lacks prioritization; that is, the importance of each input parameter relative to others still remains undefined. Therefore, future wet-laboratory and computational studies will not only have to integrate additional or exclude existing determinants for special migration modes and contexts, but they also should take coregulated synergistic or antagonistic multiparameter modules into account.

We gratefully acknowledge the collegial and insightful input of anonymous referee 1 who helped to substantially improve this article in scope and depth.

This work was supported by the Deutsche Forschungsgemeinschaft (FR 1 155/8-3) and the European Commission (T3Net; project no. 237946).

Submitted: 1 September 2009

Accepted: 29 October 2009

\section{References}

Alexander, S., G.E. Koehl, M. Hirschberg, E.K. Geissler, and P. Friedl. 2008. Dynamic imaging of cancer growth and invasion: a modified skin-fold chamber model. Histochem. Cell Biol. 130:1147-1154. doi:10.1007/s00418-008-0529-1

Alt-Holland, A., Y. Shamis, K.N. Riley, T.M. DesRochers, N.E. Fusenig, I.M. Herman, and J.A. Garlick. 2008. E-cadherin suppression directs cytoskeletal rearrangement and intraepithelial tumor cell migration in 3D human skin equivalents. J. Invest. Dermatol. 128:2498-2507. doi: $10.1038 /$ jid. 2008.102 
Belletti, B., M.S. Nicoloso, M. Schiappacassi, S. Berton, F. Lovat, K. Wolf, V. Canzonieri, S. D'Andrea, A. Zucchetto, P. Friedl, et al. 2008. Stathmin activity influences sarcoma cell shape, motility, and metastatic potential. Mol. Biol. Cell. 19:2003-2013. doi:10.1091/mbc.E07-09-0894

Beningo, K.A., M. Dembo, I. Kaverina, J.V. Small, and Y.L. Wang. 2001. Nascent focal adhesions are responsible for the generation of strong propulsive forces in migrating fibroblasts. J. Cell Biol. 153:881-888. doi:10.1083/jcb.153.4.881

Berton, S., B. Belletti, K. Wolf, V. Canzonieri, F. Lovat, A. Vecchione, A. Colombatti, P. Friedl, and G. Baldassarre. 2009. The tumor suppressor functions of $\mathrm{p} 27$ (kip1) include control of the mesenchymal/amoeboid transition. Mol. Cell. Biol. 29:5031-5045. doi:10.1128/MCB.00144-09

Blanchard, G.B., A.J. Kabla, N.L. Schultz, L.C. Butler, B. Sanson, N. Gorfinkiel, L. Mahadevan, and R.J. Adams. 2009. Tissue tectonics: morphogenetic strain rates, cell shape change and intercalation. Nat. Methods. 6:458464. doi:10.1038/nmeth.1327

Blaser, H., M. Reichman-Fried, I. Castanon, K. Dumstrei, F.L. Marlow, K. Kawakami, L. Solnica-Krezel, C.P. Heisenberg, and E. Raz. 2006. Migration of zebrafish primordial germ cells: a role for myosin contraction and cytoplasmic flow. Dev. Cell. 11:613-627. doi:10.1016/ j.devcel.2006.09.023

Carmona-Fontaine, C., H.K. Matthews, S. Kuriyama, M. Moreno, G.A. Dunn, M. Parsons, C.D. Stern, and R. Mayor. 2008. Contact inhibition of locomotion in vivo controls neural crest directional migration. Nature. 456: 957-961. doi:10.1038/nature07441

Carragher, N.O., S.M. Walker, L.A. Scott Carragher, F. Harris, T.K. Sawyer, V.G. Brunton, B.W. Ozanne, and M.C. Frame. 2006. Calpain 2 and Src dependence distinguishes mesenchymal and amoeboid modes of tumour cell invasion: a link to integrin function. Oncogene. 25:5726-5740. doi:10.1038/sj.onc. 1209582

Dahl, K.N., A.J. Ribeiro, and J. Lammerding. 2008. Nuclear shape, mechanics, and mechanotransduction. Circ. Res. 102:1307-1318. doi:10.1161/ CIRCRESAHA.108.173989

Davis, E.M., and J.P. Trinkaus. 1981. Significance of cell-to cell contacts for the directional movement of neural crest cells within a hydrated collagen lattice. J. Embryol. Exp. Morphol. 63:29-51.

Dickinson, R.B., S. Guido, and R.T. Tranquillo. 1994. Biased cell migration of fibroblasts exhibiting contact guidance in oriented collagen gels. Ann. Biomed. Eng. 22:342-356. doi:10.1007/BF02368241

Doyle, A.D., F.W. Wang, K. Matsumoto, and K.M. Yamada. 2009. Onedimensional topography underlies three-dimensional fibrillar cell migration. J. Cell Biol. 184:481-490. doi:10.1083/jcb.200810041

Even-Ram, S., and K.M. Yamada. 2005. Cell migration in 3D matrix. Curr. Opin. Cell Biol. 17:524-532. doi:10.1016/j.ceb.2005.08.015

Ewald, A.J., A. Brenot, M. Duong, B.S. Chan, and Z. Werb. 2008. Collective epithelial migration and cell rearrangements drive mammary branching morphogenesis. Dev. Cell. 14:570-581. doi:10.1016/j.devcel.2008.03.003

Fackler, O.T., and R. Grosse. 2008. Cell motility through plasma membrane blebbing. J. Cell Biol. 181:879-884. doi:10.1083/jcb.200802081

Farooqui, R., and G. Fenteany. 2005. Multiple rows of cells behind an epithelial wound edge extend cryptic lamellipodia to collectively drive cell-sheet movement. J. Cell Sci. 118:51-63. doi:10.1242/jcs.01577

Friedl, P. 2004. Prespecification and plasticity: shifting mechanisms of cell migration. Curr. Opin. Cell Biol. 16:14-23. doi:10.1016/j.ceb.2003.11.001

Friedl, P., and D. Gilmour. 2009. Collective cell migration in morphogenesis, regeneration and cancer. Nat. Rev. Mol. Cell Biol. 10:445-457. doi:10.1038/nrm2720

Friedl, P., and K. Wolf. 2003a. Proteolytic and non-proteolytic migration of tumour cells and leucocytes. Biochem. Soc. Symp. 70:277-285.

Friedl, P., and K. Wolf. 2003b. Tumour-cell invasion and migration: diversity and escape mechanisms. Nat. Rev. Cancer. 3:362-374. doi:10.1038/nrc1075

Friedl, P., and K. Wolf. 2008. Tube travel: the role of proteases in individual and collective cancer cell invasion. Cancer Res. 68:7247-7249. doi:10.1158/0008-5472.CAN-08-0784

Friedl, P., and K. Wolf. 2009. Proteolytic interstitial cell migration: a five-step process. Cancer Metastasis Rev. 28:129-135. doi:10.1007/ s10555-008-9174-3

Friedl, P., P.B. Noble, P.A. Walton, D.W. Laird, P.J. Chauvin, R.J. Tabah, M. Black, and K.S. Zänker. 1995. Migration of coordinated cell clusters in mesenchymal and epithelial cancer explants in vitro. Cancer Res. $55: 4557-4560$

Friedl, P., F. Entschladen, C. Conrad, B. Niggemann, and K.S. Zänker. 1998a. $\mathrm{CD} 4+\mathrm{T}$ lymphocytes migrating in three-dimensional collagen lattices lack focal adhesions and utilize betal integrin-independent strategies for polarization, interaction with collagen fibers and locomotion. Eur. J. Immunol. 28:2331-2343. doi:10.1002/(SICI)1521-4141(199808)28: $08<2331::$ AID-IMMU2331>3.0.CO;2-C
Friedl, P., K.S. Zänker, and E.B. Bröcker. 1998b. Cell migration strategies in 3-D extracellular matrix: differences in morphology, cell matrix interactions, and integrin function. Microsc. Res. Tech. 43:369-378. doi:10.1002/ (SICI)1097-0029(19981201)43:5<369::AID-JEMT3>3.0.CO;2-6

Friedl, P., S. Borgmann, and E.B. Bröcker. 2001. Amoeboid leukocyte crawling through extracellular matrix: lessons from the Dictyostelium paradigm of cell movement. J. Leukoc. Biol. 70:491-509.

Gérard, A., A.E. Mertens, R.A. van der Kammen, and J.G. Collard. 2007. The Par polarity complex regulates Rap1- and chemokine-induced T cell polarization. J. Cell Biol. 176:863-875. doi:10.1083/jcb.200608161

Giannone, G., and M.P. Sheetz. 2006. Substrate rigidity and force define form through tyrosine phosphatase and kinase pathways. Trends Cell Biol. 16:213-223. doi:10.1016/j.tcb.2006.02.005

Grinnell, F. 2008. Fibroblast mechanics in three-dimensional collagen matrices. J. Bodyw. Mov. Ther. 12:191-193. doi:10.1016/j.jbmt.2008.03.005

Gunzer, M., E. Kämpgen, E.B. Bröcker, K.S. Zänker, and P. Friedl. 1997. Migration of dendritic cells in 3D-collagen lattices. Visualisation of dynamic interactions with the substratum and the distribution of surface structures via a novel confocal reflection imaging technique. Adv. Exp. Med. Biol. 417:97-103.

Harley, B.A., H.D. Kim, M.H. Zaman, I.V. Yannas, D.A. Lauffenburger, and L.J. Gibson. 2008. Microarchitecture of three-dimensional scaffolds influences cell migration behavior via junction interactions. Biophys. $J$. 95:4013-4024. doi:10.1529/biophysj.107.122598

Haston, W.S., J.M. Shields, and P.C. Wilkinson. 1982. Lymphocyte locomotion and attachment on two-dimensional surfaces and in three-dimensional matrices. J. Cell Biol. 92:747-752. doi:10.1083/jcb.92.3.747

Hegerfeldt, Y., M. Tusch, E.B. Bröcker, and P. Friedl. 2002. Collective cell movement in primary melanoma explants: plasticity of cell-cell interaction, beta1integrin function, and migration strategies. Cancer Res. 62:2125-2130.

Huttenlocher, A., M.H. Ginsberg, and A.F. Horwitz. 1996. Modulation of cell migration by integrin-mediated cytoskeletal linkages and ligand-binding affinity. J. Cell Biol. 134:1551-1562. doi:10.1083/jcb.134.6.1551

Isenberg, B.C., P.A. Dimilla, M. Walker, S. Kim, and J.Y. Wong. 2009. Vascular smooth muscle cell durotaxis depends on substrate stiffness gradient strength. Biophys. J. 97:1313-1322. doi:10.1016/j.bpj.2009.06.021

Jiang, H., and F. Grinnell. 2005. Cell-matrix entanglement and mechanical anchorage of fibroblasts in three-dimensional collagen matrices. Mol. Biol. Cell. 16:5070-5076. doi:10.1091/mbc.E05-01-0007

Kaye, G.I., L.F. Siegel, and R.R. Pascal. 1971. Cell replication of mesenchymal elements in adult tissues. I. The replication and migration of mesenchymal cells in the adult rabbit dermis. Anat. Rec. 169:593-611. doi:10.1002/ ar.1091690309

Keren, K., Z. Pincus, G.M. Allen, E.L. Barnhart, G. Marriott, A. Mogilner, and J.A Theriot. 2008. Mechanism of shape determination in motile cells. Nature. 453:475-480. doi:10.1038/nature06952

Kulesa, P.M., and S.E. Fraser. 2000. In ovo time-lapse analysis of chick hindbrain neural crest cell migration shows cell interactions during migration to the branchial arches. Development. 127:1161-1172.

Lammerding, J., L.G. Fong, J.Y. Ji, K. Reue, C.L. Stewart, S.G. Young, and R.T Lee. 2006. Lamins A and C but not lamin B1 regulate nuclear mechanics. J. Biol. Chem. 281:25768-25780. doi:10.1074/jbc.M513511200

Lämmermann, T., and M. Sixt. 2009. Mechanical modes of 'amoeboid' cell migration. Curr. Opin. Cell Biol. 21:636-644. doi:10.1016/j.ceb.2009.05.003

Lämmermann, T., B.L. Bader, S.J. Monkley, T. Worbs, R. Wedlich-Söldner, K. Hirsch, M. Keller, R. Förster, D.R. Critchley, R. Fässler, and M. Sixt. 2008. Rapid leukocyte migration by integrin-independent flowing and squeezing. Nature. 453:51-55. doi:10.1038/nature06887

Lauffenburger, D.A., and A.F. Horwitz. 1996. Cell migration: a physically integrated molecular process. Cell. 84:359-369. doi:10.1016/ S0092-8674(00)81280-5

Li, S., J.L. Guan, and S. Chien. 2005. Biochemistry and biomechanics of cell motility. Annu. Rev. Biomed. Eng. 7:105-150. doi:10.1146/annurev. bioeng.7.060804.100340

Lo, C.M., H.B. Wang, M. Dembo, and Y.L. Wang. 2000. Cell movement is guided by the rigidity of the substrate. Biophys. J. 79:144-152. doi:10.1016/S0006-3495(00)76279-5

Maaser, K., K. Wolf, C.E. Klein, B. Niggemann, K.S. Zänker, E.B. Bröcker, and P. Friedl. 1999. Functional hierarchy of simultaneously expressed adhesion receptors: integrin alpha2beta1 but not CD44 mediates MV3 melanoma cell migration and matrix reorganization within threedimensional hyaluronan-containing collagen matrices. Mol. Biol. Cell. 10:3067-3079.

Mc Henry, K.T., R. Montesano, S. Zhu, A.B. Beshir, H.H. Tang, K.C. Yeung, and G. Fenteany. 2008. Raf kinase inhibitor protein positively regulates cellsubstratum adhesion while negatively regulating cell-cell adhesion. J. Cell. Biochem. 103:972-985. doi:10.1002/jcb.21470 
McNally, A.K., and J.M. Anderson. 2002. Beta1 and beta2 integrins mediate adhesion during macrophage fusion and multinucleated foreign body giant cell formation. Am. J. Pathol. 160:621-630.

Miron-Mendoza, M., J. Seemann, and F. Grinnell. 2008. Collagen fibril flow and tissue translocation coupled to fibroblast migration in 3D collagen matrices. Mol. Biol. Cell. 19:2051-2058. doi:10.1091/mbc.E07-09-0930

Nimnual, A.S., L.J. Taylor, and D. Bar-Sagi. 2003. Redox-dependent downregulation of Rho by Rac. Nat. Cell Biol. 5:236-241. doi:10.1038/ncb938

Nobes, C.D., and A. Hall. 1999. Rho GTPases control polarity, protrusion, and adhesion during cell movement. J. Cell Biol. 144:1235-1244. doi:10.1083/jcb.144.6.1235

Palamidessi, A., E. Frittoli, M. Garré, M. Faretta, M. Mione, I. Testa, A. Diaspro, L. Lanzetti, G. Scita, and P.P. Di Fiore. 2008. Endocytic trafficking of Rac is required for the spatial restriction of signaling in cell migration. Cell. 134:135-147. doi:10.1016/j.cell.2008.05.034

Palecek, S.P., J.C. Loftus, M.H. Ginsberg, D.A. Lauffenburger, and A.F. Horwitz. 1997. Integrin-ligand binding properties govern cell migration speed through cell-substratum adhesiveness. Nature. 385:537-540. doi: $10.1038 / 385537 \mathrm{a} 0$

Paluch, E., C. Sykes, J. Prost, and M. Bornens. 2006a. Dynamic modes of the cortical actomyosin gel during cell locomotion and division. Trends Cell Biol. 16:5-10. doi:10.1016/j.tcb.2005.11.003

Paluch, E., J. van der Gucht, and C. Sykes. 2006b. Cracking up: symmetry breaking in cellular systems. J. Cell Biol. 175:687-692. doi:10.1083/jcb.200607159

Paňková, K., D. Rösel, M. Novotný, and J. Brábek. 2009. The molecular mechanisms of transition between mesenchymal and amoeboid invasiveness in tumor cells. Cell. Mol. Life Sci. In press.

Parri, M., M.L. Taddei, F. Bianchini, L. Calorini, and P. Chiarugi. 2009. EphA2 reexpression prompts invasion of melanoma cells shifting from mesenchymal to amoeboid-like motility style. Cancer Res. 69:2072-2081. doi:10.1158/0008-5472.CAN-08-1845

Paszek, M.J., N. Zahir, K.R. Johnson, J.N. Lakins, G.I. Rozenberg, A. Gefen, C.A. Reinhart-King, S.S. Margulies, M. Dembo, D. Boettiger, et al. 2005. Tensional homeostasis and the malignant phenotype. Cancer Cell. 8:241254. doi:10.1016/j.ccr.2005.08.010

Petrie, R.J., A.D. Doyle, and K.M. Yamada. 2009. Random versus directionally persistent cell migration. Nat. Rev. Mol. Cell Biol. 10:538-549. doi: $10.1038 / \mathrm{nrm} 2729$

Peyton, S.R., P.D. Kim, C.M. Ghajar, D. Seliktar, and A.J. Putnam. 2008. The effects of matrix stiffness and RhoA on the phenotypic plasticity of smooth muscle cells in a 3-D biosynthetic hydrogel system. Biomaterials. 29:2597-2607. doi:10.1016/j.biomaterials.2008.02.005

Piperno, G., M. LeDizet, and X.J. Chang. 1987. Microtubules containing acetylated alpha-tubulin in mammalian cells in culture. J. Cell Biol. 104:289302. doi:10.1083/jcb.104.2.289

Provenzano, P.P., D.R. Inman, K.W. Eliceiri, S.M. Trier, and P.J. Keely. 2008 Contact guidance mediated three-dimensional cell migration is regulated by Rho/ROCK-dependent matrix reorganization. Biophys. J. 95:53745384. doi:10.1529/biophysj.108.133116

Rhee, S., and F. Grinnell. 2006. P21-activated kinase 1: convergence point in PDGF- and LPA-stimulated collagen matrix contraction by human fibroblasts. J. Cell Biol. 172:423-432. doi:10.1083/jcb.200505175

Ridley, A.J., M.A. Schwartz, K. Burridge, R.A. Firtel, M.H. Ginsberg, G. Borisy, J.T. Parsons, and A.R. Horwitz. 2003. Cell migration: integrating signals from front to back. Science. 302:1704-1709. doi:10.1126/science.1092053

Sabeh, F., I. Ota, K. Holmbeck, H. Birkedal-Hansen, P. Soloway, M. Balbin, C. Lopez-Otin, S. Shapiro, M. Inada, S. Krane, et al. 2004. Tumor cell traffic through the extracellular matrix is controlled by the membraneanchored collagenase MT1-MMP. J. Cell Biol. 167:769-781. doi:10.1083/ jcb. 200408028

Sabeh, F., R. Shimizu-Hirota, and S.J. Weiss. 2009. Protease-dependent versus -independent cancer cell invasion programs: three-dimensional amoeboid movement revisited. J. Cell Biol. 185:11-19. doi:10.1083/ jcb. 200807195

Sahai, E., and C.J. Marshall. 2003. Differing modes of tumour cell invasion have distinct requirements for Rho/ROCK signalling and extracellular proteolysis. Nat. Cell Biol. 5:711-719. doi:10.1038/ncb1019

Sahai, E., R. Garcia-Medina, J. Pouysségur, and E. Vial. 2007. Smurf1 regulates tumor cell plasticity and motility through degradation of RhoA leading to localized inhibition of contractility. J. Cell Biol. 176:35-42. doi:10.1083/jcb.200605135

Sanz-Moreno, V., and C.J. Marshall. 2009. Rho-GTPase signaling drives melanoma cell plasticity. Cell Cycle. 8:1484-1487.

Sanz-Moreno, V., G. Gadea, J. Ahn, H. Paterson, P. Marra, S. Pinner, E. Sahai, and C.J. Marshall. 2008. Rac activation and inactivation control plasticity of tumor cell movement. Cell. 135:510-523. doi:10.1016/j.cell.2008.09.043
Sawada, Y., M. Tamada, B.J. Dubin-Thaler, O. Cherniavskaya, R. Sakai, S. Tanaka, and M.P. Sheetz. 2006. Force sensing by mechanical extension of the Src family kinase substrate p130Cas. Cell. 127:1015-1026. doi:10.1016/j.cell.2006.09.044

Schober, M., S. Raghavan, M. Nikolova, L. Polak, H.A. Pasolli, H.E. Beggs, L.F. Reichardt, and E. Fuchs. 2007. Focal adhesion kinase modulates tension signaling to control actin and focal adhesion dynamics. J. Cell Biol. 176:667-680. doi:10.1083/jcb.200608010

Shoulders, M.D., and R.T. Raines. 2009. Collagen structure and stability. Annu. Rev. Biochem. 78:929-958. doi:10.1146/annurev.biochem.77.032207.120833

Smith, L.A., H. Aranda-Espinoza, J.B. Haun, M. Dembo, and D.A. Hammer. 2007. Neutrophil traction stresses are concentrated in the uropod during migration. Biophys. J. 92:L58-L60. doi:10.1529/biophysj.106.102822

Tamada, M., M.P. Sheetz, and Y. Sawada. 2004. Activation of a signaling cascade by cytoskeleton stretch. Dev. Cell. 7:709-718. doi:10.1016/j.devcel.2004.08.021

Teddy, J.M., and P.M. Kulesa. 2004. In vivo evidence for short- and long-range cell communication in cranial neural crest cells. Development. 131:61416151. doi:10.1242/dev.01534

Thiery, J.P. 2002. Epithelial-mesenchymal transitions in tumour progression. Nat. Rev. Cancer. 2:442-454. doi:10.1038/nrc822

Ulrich, T.A., E.M. de Juan Pardo, and S. Kumar. 2009. The mechanical rigidity of the extracellular matrix regulates the structure, motility, and proliferation of glioma cells. Cancer Res. 69:4167-4174. doi:10.1158/0008-5472. CAN-08-4859

Vaughan, R.B., and J.P. Trinkaus. 1966. Movements of epithelial cell sheets in vitro. J. Cell Sci. 1:407-413.

Vitorino, P., and T. Meyer. 2008. Modular control of endothelial sheet migration. Genes Dev. 22:3268-3281. doi:10.1101/gad.1725808

Wolf, K., and P. Friedl. 2009. Mapping proteolytic cancer cell-extracellular matrix interfaces. Clin. Exp. Metastasis. 26:289-298. doi:10.1007/ s10585-008-9190-2

Wolf, K., I. Mazo, H. Leung, K. Engelke, U.H. von Andrian, E.I. Deryugina, A.Y. Strongin, E.B. Bröcker, and P. Friedl. 2003a. Compensation mechanism in tumor cell migration: mesenchymal-amoeboid transition after blocking of pericellular proteolysis. J. Cell Biol. 160:267-277. doi:10.1083/ jcb.200209006

Wolf, K., R. Müller, S. Borgmann, E.B. Bröcker, and P. Friedl. 2003b. Amoeboid shape change and contact guidance: T-lymphocyte crawling through fibrillar collagen is independent of matrix remodeling by MMPs and other proteases. Blood. 102:3262-3269. doi:10.1182/blood-2002-12-3791

Wolf, K., Y.I. Wu, Y. Liu, J. Geiger, E. Tam, C. Overall, M.S. Stack, and P. Friedl. 2007. Multi-step pericellular proteolysis controls the transition from individual to collective cancer cell invasion. Nat. Cell Biol. 9:893-904. doi:10.1038/ncb1616

Wolf, K., S. Alexander, V. Schacht, L.M. Coussens, U.H. von Andrian, J. van Rheenen, E. Deryugina, and P. Friedl. 2009. Collagen-based cell migration models in vitro and in vivo. Semin. Cell Dev. Biol. In press.

Yamada, K.M., R. Pankov, and E. Cukierman. 2003. Dimensions and dynamics in integrin function. Braz. J. Med. Biol. Res. 36:959-966. doi:10.1590/ S0100-879X2003000800001

Yoshida, K., and T. Soldati. 2006. Dissection of amoeboid movement into two mechanically distinct modes. J. Cell Sci. 119:3833-3844. doi:10.1242/jcs.03152

Zaman, M.H., L.M. Trapani, A.L. Sieminski, A. Siemeski, D. Mackellar, H. Gong, R.D. Kamm, A. Wells, D.A. Lauffenburger, and P. Matsudaira. 2006. Migration of tumor cells in 3D matrices is governed by matrix stiffness along with cell-matrix adhesion and proteolysis. Proc. Natl. Acad. Sci. USA. 103:10889-10894. doi:10.1073/pnas.0604460103

Zhang, Z.G., I. Bothe, F. Hirche, M. Zweers, D. Gullberg, G. Pfitzer, T. Krieg, B. Eckes, and M. Aumailley. 2006. Interactions of primary fibroblasts and keratinocytes with extracellular matrix proteins: contribution of alpha2beta1 integrin. J. Cell Sci. 119:1886-1895. doi:10.1242/jcs.02921

Zhang, X., G. Jiang, Y. Cai, S.J. Monkley, D.R. Critchley, and M.P. Sheetz. 2008. Talin depletion reveals independence of initial cell spreading from integrin activation and traction. Nat. Cell Biol. 10:1062-1068. doi:10.1038/ncb1765 